\title{
Worker Commitment and Organizational Citizenship Behaviour in the Age of Wisdom: Critical Evaluations
}

\author{
Remi Chukwudi Okeke*, Desmond Okechukwu Nnamani \\ Department Of Public Administration and Local Government, University Of Nigeria, Nsukka \\ "remiokeke@gmail.com
}

\begin{abstract}
Keywords: Worker Commitment, Organizational Citizenship Behaviour, Age of Wisdom, Rational Choice Theory
\end{abstract}

\begin{abstract}
This study interrogates the notion of an envisaged age of wisdom whereby, the current information / knowledge worker era will be succeeded by a new order, in which information and knowledge will be impregnated with purpose and principles. The study thus examines the issue of worker commitment and organizational citizenship behaviour in the assumed age of wisdom. The analytical framework of the study is the rational choice theory. Precedent to the envisioned age of wisdom is the condition of putting service before self. We argued in the study that the age of wisdom-position contextually discountenances with a fundamentally contentious issue in human affairs, which has to do with whether the individual in the society is an inherently self-interested or an innately altruistic being. In the study's re-imaginations, worker commitment and organizational citizenship behaviours will (contrary to the assumptions of the age of wisdom) continue to be influenced by the intrinsic tendencies (of the homo economicus), in the regards of subjective rationality. In contrast to the assumed precedent-condition of putting service before self in the imminent age of wisdom, this study sees general continuity in subjective rationalities but with massive increases in universal productivity, arising from enduring human inventiveness and sundry efforts.
\end{abstract}

\section{Introduction}

We are witnessing an increasingly complex society everywhere. And these complexities are demonstrable by an apparent global desire for a world order that simultaneously signifies seamless processes and mammoth productivities. We accordingly reside in an era of great expectations, and on the other hand, a period of immense contradictions. In the first place, for the envisaged increases in universal productivity to translate into feasibility, the level of commitment demanded of the worker has similarly become unprecedented. And the employees also expect a continuing diminution in the dividing lines between management and the workforce. This furthermore creates immense challenges for organizational citizenship behaviour. We also bring into these scenarios (in this study) the notion of an age of wisdom in which the contending issues would have become gladly resolved. To what extent therefore is the assumption of an imminent age of wisdom imbued with plausibility, in the contexts of worker commitment and organizational citizenship behaviour? This is the central research question of this study and invariably it entails some re-imaginations.

Naturally, the methodology of the study is logical argumentation. The analytical (theoretical) framework of the paper is the rational choice theory. The study is indeed considered highly significant in theoretical trajectories. It accordingly highlights and interrogates the thesis of an upcoming age of wisdom, using the concepts of worker commitment and organizational citizenship behaviour (as analytical bedrocks). The work is furthermore a contribution to the universally continuing efforts on how to record enhanced productivities in ailing and other organizations. The general objective of the study therefore, is to examine the issue of worker commitment and organizational citizenship behaviour in the envisaged age of wisdom, by conducting a critical evaluation. A specific aim of the paper is accordingly, to make contributions to theory in particular, and the processes of enhanced organizational productivities in general. 


\section{Analytical Framework of the Study: Rational Choice Theory}

Rational choice theory owes its origins to the classical works of Adam Smith and subsequently, the neoclassical contributions of William Stanley Jevons. In contemporary era however, the earliest proponent of the application of the rational-actor-models in social science scholarship was Gary Becker [51], [23], [3]. The purpose of rational choice theory (RCT) is to explain social phenomena by assuming rational choice at the actor's level [14], [24], [43, p.1]. However, RCT is not without its many critics [9], [29], [41], [22], [32], [25], [45]. Hence, according to $[9$, p.196], the rational choice approach, of which classical game theory is a variant, has been until recently, the dominant approach for conceptualizing human action in the social sciences. The theory, they opined, is focused on a few determinants of individual choices wherein the methods of aggregating social behaviour are based on the decisions of individual actors. Such concept of rationality is thus widely used in economics-models, where the individuals are also referred to as homo economicus, which means that they are rational, and self-interested [9, p.196].

The point really is that the rationality of RCT is not interpretable as commonsensical or commonplace rationality. Rational choice theory is indeed of many variants, what [9, p.200] describe as multiple theoretical initiatives, with assumptions and formulations differing from core RCT. And sometimes, in the process of propagating these RCT variations, there would seem to be a return to the commonsense-connotation of rationality. But under the essential rational choice theory, rationality remains subjective and is determined by the consistency of behaviour arising from nonaltruistic considerations. Normative and moral imputations therefore actually contradict the tenets of the theory, while its assumptions remain plausible tendencies in human behavioural patterns. In the application of rational choice theoretical tenets to this study therefore, the imperatives of worker commitment and organizational citizenship behaviour in such age of wisdom were tested on the foundation of rational choice theory.

\section{Theorizing Worker Commitment}

Employee commitment is indeed a more researched and better understood concept in human resources literature. This study is not an exercise in logomachy. But there is need for explications on why the topic of our investigation prefers worker commitment to employee commitment. Essentially therefore, the concept of "employee" immediately positions the antonym of employer. But when the notion of "worker" is suggested, no such opposite words are quickly recalled. The study's variable of the age of wisdom does not demarcate between the needs of the employees and the employers. Our concept of "worker" thus equally makes an attempt to deemphasize this dichotomy. Consequently in this study, all those who earn a living by reporting for duty on daily basis in an organization are largely workers in this location. The line of demarcation between worker commitment and "other commitments" we observe, have not even been well settled in the existing literature. Therefore, when scholars such as [7] set out to talk about worker commitment, they ended up concentrating on concepts such as organizational commitment, employee commitment and employee loyalty.

This study thus peculiarly takes a generic view of the worker, which sees management staff as workers. It accordingly considers the concept of employee commitment narrower than that of worker commitment. The word "commitment" is indeed ubiquitous and interpreted in a multitude of ways [44, p.15]. We further acknowledge that the dominant approach to the standard theorization of organizational commitment points to at least two major forms: affective organizational commitment and continuance commitment [34], [33], [10]. Our concept of worker commitment recognizes in this regard the affective and continuance commitment as a combination. While affective commitment is held to capture an employee's emotional attachment to, identification with and involvement in the organization, continuance commitment is related to an employee's economic ties to the organization and the employee's perceived costs of leaving the firm [7, p. 3-4]. There is yet a third tendency in these classifications - normative commitment - putatively relating to an employee's obligation to remain in the organisation, i.e. an employee's loyalty to their employer. 


\section{The Concept of Organizational Citizenship Behaviour}

According to [37, p.489], the syntagm, organizational citizenship behavior was first used by [2]. Subsequently, Organ [35] in [31, p. 1687] defines organizational citizenship behavior (OCB), as an individual behavior, which is discretionary, not directly or explicitly recognized by the formal reward system, and which in the aggregate, promotes the effective functioning of the organization. Organ's work otherwise refers to organizational citizenship behavior as the good soldier syndrome [30, p.739]. Bergeron et al. [4, p. 959] on their part posit that building on the work of [26], it was Organ [35] who coined the term, organizational citizenship behavior (OCB).

Essentially however, organizational citizenship behaviour (OCB) refers to employees' extra role and discretionary behaviours that can contribute to organizational performance. It is generally categorized into two types: (a) interpersonally directed OCB (OCB-I) that benefits others, such as helping others who are behind in their work, and (b) organizationally directed OCB (OCB-O) that benefits the organization in general, e.g., obeying the rules of the organization when others are not present [49], [36], [13, p.857-858]. Organizations indeed seek members who display organizational citizenship behaviour [20, p. 702].

OCBs by definition are not typically included in formal job descriptions, but serve to nourish the social-psychological work context in ways that facilitate task performance and overall organizational well being [39], [42, p.96]. Shin et al. [47] refer to organizational citizenship behavior (OCB) as discretionary, extra-role behavior beyond job descriptions. OCB may further be categorized into maintenance and change OCB. Maintenance OCB encompasses behaviours intended to sustain the status quo and affiliative behaviours purported to support relationships. While the OCB literature has been dominated by maintenance OCB, a growing body of research has highlighted the importance of change OCB in organizations. Change OCB thus refers to constructive efforts to identify and implement changes with regard to work methods, policies, and procedures [48], [5], [12], [47, p.3].

OCB has also been seen as discretionary behaviours that go above and beyond the call of duty, which help develop and maintain a favorable social and psychological climate, organizational efficiency, and effectiveness [28, p.499], [36], [40]. In the final analysis, organizational citizenship behaviour (OCB) is a term that encompasses anything positive and constructive that workers do of their own volition, which supports co-workers in their individual roles and benefits the company as a whole. Typically, employees who frequently engage in OCB may not always be the top performers (though they could be, as task performance is related to OCB), but they are the ones who are known to 'go the extra mile' or 'go above and beyond' the minimum efforts required to do a merely satisfactory job [52, p. 1].

\section{The Age of Wisdom: An Explication}

The Seven Habits of Highly Effective People is classifiable as Steven R. Covey's magnum opus (the kernel of the seminal work is beside the point for our present purposes). Covey [16] is apparently a sequel to that earlier great work. In this follow-on contribution, Covey [16, p. 12] identifies the five stages of civilization's voice as: first, the hunter and gatherer age; second, the agricultural age; third, the industrial age; fourth, the information / knowledge worker age; and finally, an emerging age of wisdom. He argues that we currently live in a knowledge worker age but operate our organizations in a controlling industrial age-model that absolutely suppresses the release of human potential. Under this scenario, he contends, voice has become essentially irrelevant. Then over time, both leaders and followers confirm their roles in an unconscious pact of codependence [16].

A widespread reluctance on the part of followers to take initiative, to act independently, accordingly fuels the formal leader's imperative to direct or manage their subordinates. This they believe is what they must do in order to get followers to act. The leaders and followers thus disempower themselves, believing that others must change before their own circumstances can improve [16]. The preceding viewpoints, we add, are certainly issues of inverted worker 
commitment and converse organizational citizenship behaviour. The character of society, individuals and organizations are accordingly ultimately expected to have been positively transformed in the fifth stage of this classificatory scheme - the age of wisdom.

According to Covey, precedent to the age of wisdom is the condition of putting service before self. He believes that the current millennium will become the age of wisdom, which will come about either through force of circumstance that humbles people or through the force of conscience or perhaps both. And in the age of wisdom, information and knowledge will be impregnated with purpose and principles. Basically, Covey opines that one obtains wisdom when information and knowledge are impregnated with worthy purposes and principles. Hence, despite the wonders of the information and knowledge worker age, it is noteworthy that information is not wisdom and knowledge also is not wisdom. In Covey's estimation therefore, the current information / knowledge worker age will be succeeded by the age of wisdom. And in the context of this study, under the age of wisdom, worker commitment and organizational citizenship behaviour would have become normal issues. Workers and what remains of management would have invariably all become accustomed to putting service before self.

\section{Critical Evaluation(s)}

What does Covey truly imply by an age of wisdom? There are two possible interpretations. The first refers to an era when wisdom would be of immense commonplace-manifestation. Consequently, we instantly opine that the theses in the envisaged age of wisdom are merely speculative (more of the inventions of a fecund mind). In the first instance, it contextually discountenances with a fundamentally contentious issue in human affairs, which has to do with whether the individual in the society is inherently a self-interested actor or an innately altruistic being. An assumption of this altruism is implied in the conclusions of Covey on the age of wisdom, when viewed from the prism of everyday availability of wisdom. Furthermore, there were not easily ascertainable scientific basis of arriving at such a declaration. It is not clear from Covey's demonstrations for instance, how the current terrorist upsurges on the global arena could be contained before the emergence of the age of wisdom. Would the age of wisdom therefore only be limited to the corporate circles? But according to De la Corte [18, p.1], while terrorist activity involves spreading one's ideology or carrying out attacks, it also requires strategic planning, logistical support, raising of funds, and recruiting of adherents. And these are organizational matters and issues that are also addressed in corporate entities, which pathologies usually formed the bases of Covey's otherwise seminal interventions.

De la Corte [18, p.1] highlights also that terrorism is usually promoted by minorities and the perspective of terrorists often involves a severe distortion of social reality. It is not equally certain from the position of Covey, how the universal minority-majority dichotomies would be demerged and the occasioning distortion of reality exterminated, for humanity to all begin to put service before self. We therefore posit that the nihilist and suicidal tendencies of the terrorist has negated all the argumentations that propel the economic theories of crime. And also embedded in the defeated causal explanations are all the sociological theories and their normative equivalents. What still appears standing in these regards is locatable in the rational choice theory. This of course is neither in its economics antecedents nor in the sociological trajectories but purely as a behavioural construct. Consequently, a prognosis of an approaching age of wisdom needs to account for how the current burgeoning terrorist tendencies on the global front would give way to a universal worldview of putting service before self.

Piliavin et al. [18] in similar regards found that a person's decision to violate the law is influenced by his / her respect for criminal activities. This agrees with the rationality thesis arising from consistency and self-interest (in rational choice theory). For the age of wisdom to become a reality therefore, the issues that would prevent the predisposition to law-violation should not be mere conjectural matters. Will it for instance be engendered by a certain abundance of goods, services and opportunities, emanating from the information and knowledge worker age? But the preceding era to the age of wisdom (the information and knowledge worker age) was also 
characterized in challenging undertones by Covey, whose prognosis is further re-echoed in the position of Cox et al. [17, p. 26-27]. They argue that moral reference points may play a major role in the decision to act generously, but may not also play important roles in welfare calculations? Rational choice theory is not evasive on this matter. It sees the rational individual as one who consistently acts according to his self-interested calculations. Moreover, the notion of an imminent age of wisdom indeed takes the implied concept of participatory decision-making too far. It further dispenses (unnecessarily) with the role of central leadership in the crystallization of worker commitment and the engendering of organizational citizenship behaviour (in sundry places).

According to Sato [43, p.1] rational choice theory assumes that an actor chooses an alternative that he/she believes brings about a social outcome that optimizes his/her preference under subjectively conceived constraints. Two issues are noteworthy here. Firstly, constraints make some of the possible alternatives impossible and secondly, constraints change costs and benefits of alternatives. It must further be underscored that constraints on the actor are subjectively conceived and that the actor has beliefs about the world and these constraints are a part of them [43, p.1]. Hence, it is the subjectively conceived constraints not objective constraints that affect the actor's choices of alternatives. The actor consequently chooses an alternative that he/she believes realizes a social outcome that maximizes his/her utility under subjective constraints. However, the subjective constraints are not independent of objective constraints as social resources such as money, assets, prestige, privilege, authority and power affect the formation of subjective constraints with the help of frames through which the actor views them [43, p.1-2]. This remains the scenario for all ages.

There is implied in Covey's position, this eleemosynary assumption that the workers of the world would eventually dispense with self-interests, and all begin to embrace altruistic service, against subjective rationality. But this conclusion is not framed on any logical foundation. The challenge of worker commitment and organizational citizenship behaviour therefore is the management of the subjective rationalities, not their permanent neutralization. Here is where transformational and charismatic leaderships become appealing. Such leaders (leaderships) not only recognize and reward followers' efforts, but encourage them to ask: What can I do for the organisation? Rather than 'What can the organisation do for me? By increasing the salience and alignment of followers' and organizational goals, transformational/charismatic leadership encourages followers to 'transcend their own self-interests for the sake of the team, organisation and larger polity.' By acting as role models, the leaders' behaviours not only motivate but inspire followers to 'go the extra mile' and perform beyond their expectations [46], [1], [50], [6].

Carter et al. [11] have also found positive linkages between transformational leadership and OCB. Bottomley et al. [6, p.7] further argue that the behaviours characterizing transformational leaders, will have positive effects on followers' OCBs. In the specific viewpoints of these scholars, the unselfish characteristics associated with idealized influence and individual consideration for instance, may encourage followers to act in commendable ways. Hence, transformational leaders who 'walk the talk', treat their followers fairly and show that they trust them, along with taking an interest in their individual well-being, are more likely to see similar behaviours replicated by the workforce. Citing Gilmore et al. [21], Bottomley, Mostafa, Gould-Williams and León-Cázares further posit that such leaders generate enthusiasm amongst followers to display pro-social activities such as OCBs, as they provide a role model for them to follow. They also further opine:

When transformational leaders display inspirational motivation and intellectual stimulation, they will provide an environment in which followers feel positive about their tasks at hand. Followers will have a clear future vision based on the organization's mission, which energizes them to act and take on challenging assignments. As transformational leaders encourage followers to challenge the status quo and recommend innovative solutions to remedy poor practice, then followers will feel more comfortable suggesting improvements that will impact both the psychological and social environment within the workplace (p.7-8). 
The second scenario of interpretation in the projected age of wisdom is that under such an age, only the actors with wisdom would be counted as winners and top performers. Viewed in this light therefore, the thesis of an age of wisdom is not novel. It has always been part of history, even from the days of King Solomon. Then Covey's work was essentially a proposition on the ultimate method of transiting from effectiveness to greatness, for individuals and organizations. He invariably posits that the efficiency of the formula (for transiting from effectiveness to greatness) would be most potent in the age of wisdom. For organizations (and by implication, for individuals in organizations) we argue that it is the combination of worker commitment and organizational citizenship behaviour that leads to the requisite greatness [8], [27, p.162]. According to Schwartz [44, p. 16-17] also, the empirical study of commitment does not quite seem to fully capture the "call" of commitment as a source of power in our lives as scientific studies often do not have the power of stories. Consequently, he argues, the humanities can also help us glean and grasp the ways in which our lives are shaped by this mysterious yet powerful call to commitment as illustrated by stories of commitment found in history, biographies, and the sacred scriptures across religious traditions. Woven together therefore, these various sources tell us that our commitments:

- Give us direction

- Shape our behavior and conduct

- Change us

- Place demands on us

- Help us know when to take a stand or to show resolve

- Shape our notions of accomplishment and achievement

- Motivate and energize us

- Offer us meaning and purpose

- Form and shape our identity

- Reveal our character [44, p. 16-17].

Then to the foregoing position of Schwartz, we add that worker commitment is positively linked with organizational citizenship behaviour. And these two variables are interlinked with subjective rationalities. We highlight also that our concept of the worker is distinctively generic. And if it takes wisdom to arrive at this position of greatness, the linkage between the imminence of this new age and the current information / knowledge worker age is weak. Wisdom has been a desideratum for excellence in all ages.

\section{Conclusion}

We have in this study examined the issue of worker commitment and organizational citizenship behaviour in an envisaged age of wisdom. We accordingly critiqued the assumption of an imminent age of wisdom and its plausibility. This invariably entailed some re-imaginations. Our contribution in these regards was framed on the rational choice theory. We finally arrived at the conclusion that the thesis in the envisaged age of wisdom is weak. In the re-imaginations of this study therefore, worker commitment and organizational citizenship behaviour will continue to be influenced by the intrinsic tendencies of the homo economicus in the regards of subjective rationality. Contrary to assumed precedent-condition of putting service before self in the imminent age of wisdom therefore, we see general continuity in subjective rationalities but despite that, we envisage massive increases in universal productivity, arising from continuing human inventiveness and sundry efforts. The leadership (management) element in organizations must see the other workers as rational actors and accordingly conceive issues of worker commitment and organizational citizenship behaviour from such prisms. However, the need to continuously accord workers welfare a pride of place in management tendencies does not require an overemphasis. 


\section{References}

[1] B.M. Bass, Two decades of research and development in transformational leadership, European Journal of Work and Organizational Psychology. 8(1) (1999) 9-32.

[2] T.S. Bateman, D.W. Organ, Job satisfaction and the good soldier: The relationship between affect and employee "citizenship", Academy of Management Journal. 26(4) (1983) 587-595.

[3] G. Becker, The economic approach to human behavior, The University of Chicago Press, Chicago, 1976.

[4] D.M. Bergeron et al., Organizational citizenship behavior and career outcomes: The cost of being a good citizen, Journal of Management. 39(4) (2013) 958-984.

[5] L.A. Bettencourt, Change-oriented organizational citizenship behaviors: The direct and moderating influence of goal orientation, Journal of Retailing. 80(3) (2004) 165-180.

[6] P. Bottomley et al., The impact of transformational leadership on organizational citizenship behaviours: The contingent role of public service motivation, British Journal of Management. 27(2) (2016) 390-405.

[7] S. Brown, R. McNabb, K. Taylor, Firm performance, worker commitment and loyalty. Sheffield economic research paper series (SERP) Number: 2006005, University of Sheffield, United Kingdom, 2007.

[8] S. Brown et al., Workplace performance, worker commitment, and loyalty, Journal of Economics \& Management Strategy. 20(3) (2011) 925-955.

[9] T.R. Burns, E. Roszkowska, Rational choice theory: Toward a psychological, social, and material contextualization of human choice behavior, Theoretical Economics Letters. 6(2) (2016) 195-207.

[10] A. Carmeli, A. Freund, Work commitment, job satisfaction, and job performance: An empirical investigation, International Journal of Organization Theory \& Behavior. 7(3) (2004) 289309.

[11] M.Z. Carter et al., Transformational leadership, interactional justice, and organizational citizenship behavior: The effects of racial and gender dissimilarity between supervisors and subordinates, Group \& Organization Management. 39(6) (2014) 691-719.

[12] J.N. Choi, Change-oriented organizational citizenship behavior: Effects of work environment characteristics and intervening psychological processes, Journal of Organizational Behavior. 28(4) (2007) 467-485.

[13] J.S. Chun et al., How does corporate ethics contribute to firm financial performance? The mediating role of collective organizational commitment and organizational citizenship behavior, Journal of Management. 39(4) (2013) 853-877.

[14] J.S. Coleman, Foundations of social theory, Cambridge, MA: The Belknap Press of Harvard University Press, 1990.

[15] S.R. Covey, The seven habits of highly effective people, Free Press, New York, 1989.

[16] S.R. Covey, The 8th habit: From effectiveness to greatness, Simon \& Schuster, London, 2004.

[17] J.C. Cox et al., Moral costs and rational choice: Theory and experimental evidence, Cambridge, MA: National Bureau of Economic Research, 2016.

[18] L. De la Corte, Explaining terrorism: A psychosocial approach, Perspectives on Terrorism, $1(2)(2010) 1-10$. 
[19] T. Dewett, A.S. Denisi, What motivates organizational citizenship behaviors? Exploring the role of regulatory focus theory, European Journal of Work and Organizational Psychology. 16(3) (2007) 241-260.

[20] S.Z. Eyupoglu, The organizational citizenship behaviour of academic staff in North Cyprus, Procedia Economics and Finance. 39 (2016) 701-704.

[21] P.L. Gilmore et al., Positive affectivity neutralizes transformational leadership's influence on creative performance and organizational citizenship behaviors, Journal of Organizational Behavior. 34(8) (2013) 1061-1075.

[22] D.P. Green, I. Shapiro, Pathologies of rational choice theory: A critique of applications in political science, New Haven, CT: Yale University Press, 1994.

[23] T. Grüne-Yanoff, Paradoxes of rational choice theory, in: S. Roeser et al. (Eds.), Handbook of Risk Theory: Epistemology, Decision Theory, Ethics and Social Implications of Risk, Vol. 1, Springer Science \& Business Media, 2012, pp. 499-516.

[24] M. Hechter, S. Kanazawa, Sociological rational choice theory, Annual Review of Sociology. 23 (1997) 191-214.

[25] D. Kahneman, P. Slovic, A. Tversky (Eds.), Judgments under uncertainty: Heuristics and biases, Cambridge University Press, Cambridge, 1982.

[26] D. Katz, The motivational basis of organizational behavior, Behavioral Science. 9(2) (1964) 131-146.

[27] E.L. Kick, J.C. Fraser, B.L. Davis, Performance management, managerial citizenship and worker commitment: A study of the United States postal service with some global implications, Economic and industrial democracy. 27(1) (2006) 137-172.

[28] C.F. Lam et al., Job insecurity and organizational citizenship behavior: Exploring curvilinear and moderated relationships, Journal of Applied Psychology. 100(2) (2015) 499-510.

[29] M. Luebker, Income inequality, redistribution, and poverty: contrasting rational choice and behavioral perspectives, Review of Income and Wealth. 60(1) (2014) 133-154.

[30] S.M. Magdalena, The effects of organizational citizenship behavior in the academic environment, Procedia-Social and Behavioral Sciences. 127 (2014) 738-742.

[31] F.K. Matta et al., Does seeing "eye to eye" affect work engagement and organizational citizenship behavior? A role theory perspective on LMX agreement, Academy of Management Journal. 58(6) (2015) 1686-1708.

[32] P. Mirowski, More heat than light: Economics as social physics, physics as nature's economics, Cambridge University Press, Cambridge, United Kingdom, 1989.

[33] P.C. Morrow, The theory and measurement of work commitment, JAI Press Inc., Greenwich, Connecticut, 1993.

[34] P.C. Morrow, K. Eastman, J.C. McElroy, Concept redundancy and rater naivety in organizational research, Journal of Applied Social Psychology. 21(3) (1991) 219-232.

[35] D.W. Organ, Organizational citizenship behavior: The good soldier syndrome. Lexington, MA, England: Lexington Books, 1988.

[36] D.W. Organ, P.M. Podsakoff, S.B. MacKenzie, Organizational citizenship behavior: Its nature, antecedents, and consequences, Thousand Oaks, CA: Sage, 2006.

[37] M. Pavalache-Ilie, Organizational citizenship behaviour, work satisfaction and employees' personality, Procedia-Social and Behavioral Sciences. 127 (2014) 489-493. 
[38] I. Piliavin et al., Crime, deterrence, and rational choice, American Sociological Review. 51(1) (1986) 101-119.

[39] P.M. Podsakoff et al., Organizational citizenship behaviours: A critical review of the theoretical and empirical literature and suggestions for future research, Journal of Management. 26(3) (2000) 513-563.

[40] N.P. Podsakoff et al., Individual-and organizational-level consequences of organizational citizenship behaviors: A meta-analysis, Journal of Applied Psychology. 94(1) (2009) 122-141

[41] O. Renn et al., The rational actor paradigm in risk theories: Analysis and critique, in: M.J. Cohen (Ed.), Risk in the Modern Age: Social Theory, Science and Environmental DecisionMaking, Houndmills, Palgrave Macmillan, Basingstoke, 2000.

[42] P. Ruiz-Palomino, R. Martínez-Cañas, Ethical culture, ethical intent, and organizational citizenship behavior: The moderating and mediating role of person-organization fit, Journal of Business Ethics. 120(1) (2014) 95-108.

[43] Y. Sato, Rational choice theory. Sociopedia of the International Sociological Association (ISA) and SAGE, 2013. Doi: 10.1177/205684601372

[44] A.J. Schwartz, The call of commitment: implications for the direction and intensity of our leader behaviors and actions, The Journal of Character \& Leadership Integration. 4(1) (2017) 15-21.

[45] A.K. Sen, Rational fools: A critique of the behavioral foundations of economic theory, Philosophy and Public Affairs. 6(4) (1977) 317-44.

[46] B. Shamir, R.J. House, M.B. Arthur, The motivational effects of charismatic leadership: A self-concept based theory, Organization Science. 4(4) (1993) 577-594.

[47] Y. Shin et al., Does leader-follower regulatory fit matter? The role of regulatory fit in followers' organizational citizenship behavior, Journal of Management. 20(10) (2014) 1-23.

[48] L. Van Dyne, L.L. Cummings, J.M. McLean Parks, Extra-role behaviors: In pursuit of construct and definitional clarity (A bridge over muddied waters), in: L.L. Cummings, B.M. Staw (Eds.), Research in organizational behavior. 17 (1995) 215-285.

[49] L.J. Williams, S.E. Anderson, Job satisfaction and organizational commitment as predictors of organizational citizenship and in-role behaviors, Journal of Management. 17(3) (1991) 601-617.

[50] B.E. Wright, S.K. Pandey, Transformational leadership in the public sector: does structure matter? Journal of Public Administration Research and Theory. 20(1) (2010) 75-89.

[51] M. Zafirovski, Rational choice theory at the origin? Forms and social factors of "irrational choice", Social Epistemology. 30(5-6) (2016) 728-763.

[52] D. Zhang, Organizational citizenship behavior, PSYCH761White Paper (OCB), 2011. Retrieved from: https://cdn.auckland.ac.nz. 